\title{
Demografia de perfilhos basilares em pastagem de Brachiaria decumbens adubada com nitrogênio ${ }^{1}$
}

\section{Rodrigo Vieira de Morais ${ }^{2}$, Dilermando Miranda da Fonseca ${ }^{3}$, Domicio do Nascimento Júnior $^{3}$, José Ivo Ribeiro Junior ${ }^{4}$, Jailson Lara Fagundes ${ }^{5}$, Luciano de Melo Moreira ${ }^{5}$, Claudio Mistura ${ }^{5}$, Janaina Azevedo Martuscello ${ }^{5}$}

\author{
1 Parte da dissertação de Mestrado do primeiro autor, apresentada à UFV. \\ 2 MSc. em Zootecnia (Forragicultura e Pastagens) pela UFV. \\ ${ }^{3}$ Departamento de Zootecnia - UFV. \\ ${ }^{4}$ Departamento de Informática - UFV. \\ 5 Pós-graduação em Zootecnia (Forragicultura e Pastagens) pela UFV.
}

RESUMO - Em um ensaio de pastejo sob lotação contínua avaliaram-se as taxas de aparecimento, mortalidade e sobrevivência, a porcentagem de florescimento e a densidade populacional de perfilhos basilares em uma pastagem de Brachiaria decumbens adubada com quatro doses de nitrogênio (75, 150, 225 e $300 \mathrm{~kg} / \mathrm{ha}$.ano). Os resultados foram agrupados em três períodos do ano: fevereiro a abril, maio a agosto e setembro a novembro. O experimento foi conduzido em parcelas subdivididas no tempo segundo delineamento em blocos completos casualizados, com duas repetições. A adubação nitrogenada foi parcelada em três aplicações: a primeira no mês de dezembro de 2002, a segunda em janeiro de 2003 e a terceira em março de 2003. A avaliação demográfica foi realizada em perfilhos demarcados por um anel de PVC. A partir da população inicial, a cada mês os perfilhos foram identificados utilizando-se arames de cores diferenciadas. Para avaliação da densidade populacional de perfilhos basilares (vegetativos, reprodutivos e mortos), foram colhidas amostras de plantas delimitadas por três quadrados de $25 \times 25 \mathrm{~cm}$ por piquete. A adubação nitrogenada influenciou as taxas de aparecimento e sobrevivência, o número de perfilhos vegetativos e a mortalidade de perfilhos na primeira e segunda gerações após o início das avaliações. As maiores taxas de aparecimento ocorreram nos períodos de fevereiro/abril e setembro/novembro, enquanto a maior taxa de mortalidade, em fevereiro/abril. A densidade populacional de perfilhos também variou, atingido os maiores valores no período de fevereiro/abril. O florescimento do capim-braquiária se concentrou nos meses de fevereiro a maio.

Palavras-chave: capim-braquiária, lotação contínua, manejo, perfilhamento

\section{Demography of basal tillers in pasture of Brachiaria decumbens fertilized with nitrogen}

\begin{abstract}
It was evaluated tiller appearance, mortality and survival rates, the flowering percentage and the population density of basal tillers in pasture of Brachiaria decumbens under four doses of nitrogen (75, 150, 225 and $300 \mathrm{~kg} / \mathrm{ha} / \mathrm{year})$, in three periods of the year: February to April, May to August and September to November. The experiment was conducted in a completely randomized design with periods as a split plot feature, with two replications. The nitrogen fertilization was split in three applications the first in December (2002), second in January (2003) and the third in March (2003). The evaluation of demography of basal tillers was accomplished by initial demarcation of all the tillers contained within a ring of PVC, followed by monthly identification of new tillers with wires of different colors. Evaluation of the population density of basal tillers (vegetative, reproductive and dead tillers) was performed from samples of plants harvested within $25 \times 25 \mathrm{~cm}$ three squares from each paddock. The nitrogen fertilization positively influenced the tiller appearance, mortality and survival rates, number of vegetative tillers and the tillers mortality in the generations 1 and 2. Rates of tiller appearance were higher in February/April and September/November, while the rate of tiller mortality was higher in February/April period. Tiller population density also varied over the periods, higher figures being observed in Febrary/April period. The flowering of the Signalgrass flowering was most intense from February to May.
\end{abstract}

Key Words: continuous stocking, pasture management, signalgrass, tillering

\section{Introdução}

Em pastagens, o perfilho consite na unidade básica das gramíneas, que utilizam o perfilhamento como forma de crescimento e, sobretudo, como forma de sobrevivência na pastagem (Hodgson, 1990).

Nas espécies de gramíneas perenes ocorrem, quanto à origem, dois grupos de perfilhos: os basilares, que se 
originam da base da planta e possuem seu próprio sistema radicular, e os axilares, que surgem a partir de nós superiores dos colmos basais e não desenvolvem sistema radicular independente. Segundo Mozzer (1993), no capim-elefante, as brotações das gemas axilares correspondem a 70-80\% do número total de perfilhos e são responsáveis por apenas $20 \%$ da produção de massa verde, ao passo que os 20-30\% dos perfilhos basilares resultam em aproximadamente $80 \%$ da produção total de massa verde.

Segundo Langer (1963), o perfilhamento é influenciado por fatores de ambiente, destacando-se a temperatura e o suprimento de água e de nutrientes, principalmente de nitrogênio $(\mathrm{N})$, que assume papel importante no crescimento e na produção das plantas forrageiras, pois seu suprimento eleva o número de perfilhos por planta (Langer, 1963; McKenzie, 1998; Alexandrino et al., 1999; Garcez Neto et al., 2002; Bahmani et al., 2002). Nabinger (1996) atribuiu o efeito positivo do $\mathrm{N}$ sobre o perfilhamento à maior rapidez de formação das gemas axilares e à iniciação dos perfilhos correspondentes.

Um sinal para a ativação das gemas e para produção de novos perfilhos é a qualidade da luz incidente após o pastejo. A qualidade da luz também é influenciada pela época do ano, que promove diferenças na densidade populacional de perfilhos em diferentes períodos (Santos et al., 1999; Carvalho et al., 2000; Uebele, 2002; Fagundes et al., 2005). De fato, a menor intensidade de radiação e a reduzida relação dos comprimentos de onda vermelho/vermelho extremo inibem o perfilhamento (Deregibus et al., 1983). Outra importante causa da redução do número de perfilhos é o balanço negativo de energia, resultado da competição por luz. Davies et al. (1983), em experimento com azevém perene, demonstraram que maior quantidade de fotoassimilados era alocada para o crescimento de perfilhos existentes em relação àquela alocada para o desenvolvimento de novos perfilhos, em plantas sombreadas.

As taxas de aparecimento, florescimento e morte de perfilhos determinam sua contribuição para a composição morfológica da pastagem de forma a permitir maior ou menor acúmulo de forragem em diferentes épocas do ano (Korte, 1986; Hernandez Garay et al., 1997). Matthew et al. (2000) avaliaram o perfilhamento em 13 experimentos e observaram, em muitos casos, variação estacional das taxas de aparecimento e morte de perfilhos, o que pode estar relacionado às estratégias de persistência das plantas.

Neste estudo, propôs-se avaliar o perfilhamento basilar em Brachiaria decumbens cv. Basilisk sob pastejo em lotação contínua com adubação nitrogenada em três períodos do ano.

\section{Material e Métodos}

O experimento foi conduzido em 2003, emuma pastagem de Brachiaria decumbens Stapf. cv. Basilisk estabelecida em 1997, utilizada para desenvolvimento de outros projetos de pesquisa.

A área experimental pertence ao setor de Forragicultura no Departamento de Zootecnia da Universidade Federal de Viçosa, em Viçosa-MG $\left(20^{\circ} 45^{\prime}\right.$ de latitude sul e $42^{\circ} 51^{\prime}$ de longitude oeste e $651 \mathrm{~m}$ de altitude). O clima, pelo sistema de Köeppen, é do tipo Cwa, com precipitação anual média em torno de $1.340 \mathrm{~mm}$, umidade relativa média do ar de $80 \%$ e temperaturas médias máximas e mínimas de 27,3 e $14,9^{\circ} \mathrm{C}$, respectivamente. As médias mensais de temperatura, precipitação e insolação referentes ao ano do experimento são apresentadas na Tabela 1 .

O solo da área experimental é classificado como latossolo vermelho-amarelo (EMBRAPA, 1999) de textura argilosa, relevo medianamente ondulado, com as seguintes características químicas (média dos oito piquetes) na camada de 0 a $20 \mathrm{~cm}$ de profundidade: $\mathrm{pH}$ em água $=5,2 ; \mathrm{P}=5,18$; $\mathrm{K}=148,75 \mathrm{mg} / \mathrm{dm}^{3}$ ( Mehlich-1); $\mathrm{Ca}=2,83 ; \mathrm{Mg}=0,82$; $\mathrm{Al}=0,13 \mathrm{cmolc} / \mathrm{dm}^{3}$ (Extrator $\left.\mathrm{KCl}-1 \mathrm{~mol} / \mathrm{L}\right)$; e matéria orgânica $=4,24 \mathrm{dag} / \mathrm{kg}$.

Em decorrência do resultado de análise do solo, aplicaram-se $100 \mathrm{~kg} /$ ha de $\mathrm{P}_{2} \mathrm{O}_{5}$ (superfosfato simples), mas não foram aplicados calcário e adubo potássico.

O experimento foi arranjado em parcelas subdivididas segundo delineamento em blocos completos casualizados, com duas repetições. Os tratamentos consistiram de quatro doses de $\mathrm{N}(75,150,225$ e $300 \mathrm{~kg} / \mathrm{ha}$.ano) e três períodos de avaliação (subparcelas). As subparcelas foram caracterizadas de acordo com a época do ano e a distribuição do adubo nitrogenado. Assim, os meses de fevereiro a abril foram agrupados por representarem o parcelamento da adubação e a época de condições climáticas favoráveis; os meses de maio a agosto, por representarem o resíduo da adubação mais a época seca do ano; e os meses de setembro a novembro, por caracterizarem o resíduo da adubação mais o período de transição seca/águas. As áreas dos piquetes variaram de 0,2 a 0,4 ha. Para proporcionar número de animais/piquete mais uniforme em todo o experimento, áreas menores receberam doses maiores de $\mathrm{N}$ e áreas maiores, menores doses de $\mathrm{N}$. O adubo nitrogenado foi distribuído em três aplicações: 10/12/2002,29/01/2003 e 17/03/2003.

Foram utilizados bezerros machos $\mathrm{H} / \mathrm{Z}$ com peso inicial de 180 a $210 \mathrm{~kg}$, mantendo-se o mínimo de dois animais por piquete durante os meses de janeiro a abril. No período de maio a setembro, em razão das condições climáticas desfavoráveis, da baixa temperatura e da reduzida precipitação 
Tabela 1 - Precipitação pluvial e médias mensais de temperaturas máximas e mínimas e insolação durante o período experimental Table 1 - Pluvial precipitation and monthly average maximum, mean and minimum temperatures and sunstroke during the experimental period

\begin{tabular}{|c|c|c|c|c|c|}
\hline \multirow[t]{2}{*}{$\begin{array}{l}\text { Mês/2003 } \\
\text { Month/2003 }\end{array}$} & \multicolumn{3}{|c|}{$\begin{array}{c}\text { Temperatura }\left({ }^{\circ} \mathrm{C}\right) \\
\text { Temperature }\left({ }^{\circ} \mathrm{C}\right)\end{array}$} & \multirow{2}{*}{$\begin{array}{l}\text { Precipitação } \\
\text { Precipitation } \\
(\mathrm{mm})\end{array}$} & \multirow{2}{*}{$\begin{array}{l}\text { Insolação } \\
\text { Sunstroke } \\
\text { (horas/dia) } \\
\text { (hour/day) }\end{array}$} \\
\hline & $\begin{array}{l}\text { Máxima } \\
\text { Maximum }\end{array}$ & $\begin{array}{l}\text { Mínima } \\
\text { Minimum }\end{array}$ & $\begin{array}{l}\text { Média } \\
\text { Average }\end{array}$ & & \\
\hline Fevereiro & 31,09 & 19,05 & 23,7 & 27,90 & 8,66 \\
\hline \multicolumn{6}{|l|}{ February } \\
\hline $\begin{array}{l}\text { Março } \\
\text { March }\end{array}$ & 29,32 & 19,16 & 22,7 & 81,40 & 5,52 \\
\hline $\begin{array}{l}\text { Abril } \\
\text { April }\end{array}$ & 28,36 & 16,57 & 21,4 & 16,60 & 6,51 \\
\hline $\begin{array}{l}\text { Maio } \\
\text { May }\end{array}$ & 26,03 & \multicolumn{4}{|c|}{ May } \\
\hline \multicolumn{5}{|l|}{ June } & 8,42 \\
\hline $\begin{array}{l}\text { Julho } \\
\text { July }\end{array}$ & 25,42 & 10,19 & 16,1 & 7,50 & 7,93 \\
\hline $\begin{array}{l}\text { Agosto } \\
\text { August }\end{array}$ & 24,40 & \multicolumn{4}{|c|}{ August } \\
\hline \multicolumn{6}{|l|}{ September } \\
\hline $\begin{array}{l}\text { Outubro } \\
\text { October }\end{array}$ & 28,06 & 15,72 & 20,7 & 27,80 & 5,72 \\
\hline $\begin{array}{l}\text { Novembro } \\
\text { November }\end{array}$ & 27,82 & 17,80 & 21,6 & 163,80 & 4,41 \\
\hline
\end{tabular}

Fonte: Departamento de Engenharia Agrícola, UFV.

Source: Agricultural Engineering Department, UFV.

pluvial, os animais foram retirados dos piquetes e retornaram em outubro e novembro quando as condições novamente foram favoráveis ao crescimento da forrageira. A altura média da pastagem durante as avaliações foi mantida em aproximadamente $20 \mathrm{~cm}$ (Cavalcante, 2001) por meio da adição ou retirada de animais nas unidades experimentais. A dinâmica de perfilhamento foi avaliada por um período de dez meses, de fevereiro a novembro de 2003.

A altura do pastagem foi monitorada semanalmente por meio da tomada de 50 medidas em cada piquete. Além dos dois animais-teste por piquete, animais adicionais foram colocados ou retirados no caso de a pastagem estar acima ou abaixo da altura desejada $(20 \mathrm{~cm})$.

A avaliação dos padrões demográficos dos perfilhos e de suas respectivas taxas de aparecimento, mortalidade, sobrevivência e florescimento foi realizada segundo Carvalho et al. (2000). Foram utilizados três anéis de PVC de $0,049 \mathrm{~m}^{2}$ de área ( $25 \mathrm{~cm}$ de diâmetro e $8 \mathrm{~cm}$ de altura) por piquete. Os anéis foram alocados em locais representativos de cada piquete, ou seja, onde estivesse com $20 \mathrm{~cm}$ de altura, e introduzidos no solo a $6,0 \mathrm{~cm}$ de profundidade, mantendo-se a 2,0 $\mathrm{cm}$ acima da superfície. Todos os perfilhos mantidos no círculo de PVC foram contados e, a partir daí, foram marcados a cada 28 dias com arame liso revestido de plástico de diferentes cores, que representavam cada geração de perfilhos. Em cada período de 28 dias, os perfilhos foram recontados, calculando-se as taxas de mortalidade, aparecimento, sobrevivência e florescimento de perfilhos basilares, a saber:

no de perf. novos

(última geração marcada)

Taxa de aparecimento $=\quad \times 100$

$\mathrm{n}$ o de perfilhos totais existentes (gerações marc. ant.)

Perf.marc.anteriores-

Perf. sobrev.(contagem. atual)

Taxa de mortalidade $=$ $\mathrm{x} 100$ $\mathrm{n}$ o total de perfilhos na marc. anterior no perfilhos reprodutivos (marcação atual)

Taxa de florescimento $=$ x 100

$\mathrm{n} \underline{\mathrm{o}}$ perfilhos existentes (marcações anteriores)

no- perf. da marc. anterior vivos na marc. atual

Taxa de sobrevivência $=$ $x 100$ $\mathrm{n}$ o total de perfilhos vivos na marcação anterior 
As taxas de aparecimento, mortalidade, sobrevivência e florescimento em cada anel foram somadas e o total foi dividido por três (três anéis/piquete), obtendo-se uma média para cada unidade experimental (piquete). A partir destas médias, calcularam-se as taxas médias mensais, por meio da média ponderada do número de dias em cada mês. Essas taxas foram agrupadas por períodos de avaliação, de modo que o Período-1 correspondeu à média dos meses de fevereiro a abril; o Período-2, à média dos meses de maio a agosto; e o Período-3, à média dos meses de setembro a novembro.

A análise dos valores de perfilhos mortos por geração foi realizada conforme proposta de Matthew et al. (2000); o número de perfilhos de cada geração, em cada data de avaliação, foi transformado para escala logarítmica, de forma que uma regressão simples entre esses valores e o número de dias de avaliação (0 a 290) resultasse em equações lineares.

A inclinação destas retas, dada pelos seus coeficientes angulares, reflete o padrão de mortalidade das gerações de perfilhos. Retas paralelas ou de coeficientes angulares semelhantes indicam padrão homogêneo e uniforme de mortalidade. Dessa forma, efetuou-se a análise de regressão com valores dos coeficientes angulares das retas pertencentes a cada geração estudada, de acordo com as doses de $\mathrm{N}$.

A densidade populacional de perfilhos foi avaliada a cada 28 dias, durante nove meses, considerando-se o número de perfilhos basilares, discriminados em vegetativos, mortos e reprodutivos. Foram colhidas, rente ao solo, três amostras de capim-braquiária $(20 \mathrm{~cm})$ por piquete. Cada amostra consistiu de uma área delimitada por um quadrado de $25 \times 25 \mathrm{~cm}\left(0,0625 \mathrm{~m}^{2}\right)$.

Os dados foram analisados por meio do programa estatístico SAEG. Para os tratamentos primários (doses de $\mathrm{N}$ - tratamentos quantitativos), foram realizadas análises de regressão com seleção de modelos lineares significativos a
5\% de probabilidade, dentro de cada período avaliado e, para os períodos de avaliação (fatores qualitativos), foi aplicado o teste Tukey a 5\% de probabilidade, para cada dose de $\mathrm{N}$.

Avaliaram-se as taxas de aparecimento, mortalidade e sobrevivência e a densidade populacional de perfilhos basilares. Para os percentuais de perfilhos reprodutivos, não foi efetuada análise estatística, uma vez que um número muito grande de zeros foi registrado para este tipo de contagem.

\section{Resultados e Discussão}

A taxa de aparecimento de perfilhos no período de fevereiro a abril foi superior $(\mathrm{P}<0,05)$ à do período de maio a agosto, mas não diferiu $(\mathrm{P}>0,05)$ daquela registrada no período de setembro a novembro com as doses de 75 e $150 \mathrm{~kg} /$ ha de $\mathrm{N}$ (Tabela 2) e essas taxas não diferiram entre os períodos nas doses de 225 e $300 \mathrm{~kg} / \mathrm{ha}$ de N. Esses resultados podem ser atribuídos às melhores condições de ambiente (temperatura, precipitação e insolação diárias) verificadas durante os meses de fevereiro a abril e setembro a novembro (Tabela 1) e são semelhantes aos relatados por Carvalho et al. (2000), que encontraram maiores taxas de perfilhamento no verão, em capim-tifton 85 .

Também constatou-se efeito linear do resíduo das doses de $\mathrm{N}$ sobre as taxas de aparecimento de perfilhos nos período de maio a agosto e setembro a novembro (Tabela 2), provavelmente em razão do maior aparecimento de folhas, relacionado ao aumento da disponibilidade de N (Garcez Neto et al., 2002; Martuscello et al., 2005), potencializando o surgimento de novos perfilhos com o aumento da ocupação de sítios (Lemaire, 1985, citado por Nabinger \& Pontes, 2001).

A taxa de mortalidade de perfilhos em capim-braquiária foi influenciada pelos períodos de avaliação e pelas doses

Tabela 2 - Taxas de aparecimento de perfilhos basilares (perfilhos/100 perfilhos) em pastagem de Brachiaria decumbens adubadas com quatro doses de $\mathrm{N}$

Table 2 - Appearance rate of basal tillers (tillers/100 tillers) in a pasture of Brachiaria decumbens fertilized four doses of $\mathrm{N}$

\begin{tabular}{|c|c|c|c|c|c|c|}
\hline \multirow[b]{2}{*}{$\begin{array}{l}\text { Período } \\
\text { Period }\end{array}$} & \multicolumn{4}{|c|}{$\begin{array}{l}\text { Doses de nitrogênio }(\mathrm{kg} / \mathrm{ha}) \\
\text { Doses of } N\end{array}$} & \multirow[t]{2}{*}{$\begin{array}{c}\text { Equação de regressão } \\
\text { Regression equation }\end{array}$} & \multirow[t]{2}{*}{$\mathrm{R}^{2}(\%)$} \\
\hline & 75 & 150 & 225 & 300 & & \\
\hline $\begin{array}{l}\text { Fev }- \text { Abr } \\
F e b-A p r\end{array}$ & 33,80 a & $40,48 \mathrm{a}$ & $31,92 \mathrm{a}$ & $35,88 \mathrm{a}$ & $\hat{Y}=35,52$ & \\
\hline $\begin{array}{l}\text { Mai - Ago } \\
\text { May-Aug }\end{array}$ & $10,42 b$ & $12,34 b$ & $14,66 \mathrm{a}$ & $19,34 \mathrm{a}$ & $\bar{Y}=6,92+0,038 * \mathrm{~N}$ & 95,27 \\
\hline $\begin{array}{l}\text { Set - Nov } \\
\text { Sep-Nov }\end{array}$ & $18,77 \mathrm{ab}$ & $22,98 \mathrm{ab}$ & $24,75 \mathrm{a}$ & $27,30 \mathrm{a}$ & $\hat{\mathrm{Y}}=16,61+0,036 * \mathrm{~N}$ & 96,86 \\
\hline
\end{tabular}

Médias seguidas pela mesma letra, na coluna, não diferem $(P>0,05)$ pelo teste Tukey.

Means followed by the same letter, in the column, do not differ $(P>0.05)$ by Tukey test.

* Significativo pelo teste $t(P<0,05)$.

* Significant by t test $(P<0.05)$. 
de $\mathrm{N}$, observando-se os maiores valores $(\mathrm{P}<0,05)$ no período de fevereiro a abril para todas as doses de $\mathrm{N}$ (Tabela 3 ).

A alta mortalidade de perfilhos no período de fevereiro a abril, compensada pela alta taxa de aparecimento (Tabela 2), revelou grande renovação de perfilhos durante este período do ano. Isso é importante para a manutenção da população de perfilhos e, principalmente, para a sobrevivência da planta no ecossistema.

O efeito linear positivo $(\mathrm{P}<0,05)$ da adubação nitrogenada sobre a taxa de mortalidade de perfilhos no capim-braquiária foi observado somente no período de setembro a novembro (Tabela 3 ) e pode estar relacionado à ação deste nutriente na diminuição do tempo de vida do perfilho. Deve-se buscar espaço de tempo curto para a renovação de perfilhos em gramíneas, pois o surgimento de novos perfilhos renova a área foliar e pode melhorar o valor nutritivo da pastagem.

As doses de $\mathrm{N}$ influenciaram $(\mathrm{P}<0,05)$ apenas as gerações 1 e 2 de perfilhos, ocasionando redução no coeficiente angular (maior mortalidade) à medida que foram aumentadas as doses de N (Tabela 4). Esta tendência linear decrescente pode ser reflexo da maior freqüência de pastejo ocorrida nos tratamentos com maiores doses de N. Nestes tratamentos, aumentou-se a taxa de lotação para manter a altura da pastagem em $20 \mathrm{~cm}$. Resultados semelhantes foram observados por Carvalho (2000), em espécies de Cynodon, e por Uebele (2002), em tratamentos com maior freqüência de pastejo em Panicum maximum cv. Mombaça.

$\mathrm{O}$ incremento das doses de $\mathrm{N}$ não proporcionou elevação nos coeficientes de inclinação das gerações de perfilhos, indicando que a adubação nitrogenada não teve efeito sobre a longevidade das gerações de perfilhos no capim-braquiária (Tabela 4).

As taxas de sobrevivência de perfilhos basilares, à exceção da dose de $150 \mathrm{~kg} / \mathrm{ha}$ de $\mathrm{N}$, não diferiram $(\mathrm{P}>0,05)$ entre os períodos de avaliação (Tabela 5), provavelmente em razão do manejo da gramínea, principalmente quanto à altura da pastagem e à retirada dos animais no período de maio a agosto, em razão das características morfológicas da Brachiaria decumbens neste período.

Verificou-se efeito linear decrescente do resíduo de $\mathrm{N}$ sobre a taxa de sobrevivência de perfilhos no período de

Tabela 3 - Taxas de mortalidade de perfilhos basilares (perfilhos/100 perfilhos) em pastagem de Brachiaria decumbens adubadas com quatro doses de $\mathrm{N}$

Table 3 - Rates of mortality of basal tillers (tillers/100 tillers) in a pasture of Brachiaria decumbens fertilized four doses of $\mathrm{N}$

\begin{tabular}{|c|c|c|c|c|c|c|}
\hline \multirow[b]{2}{*}{$\begin{array}{l}\text { Período } \\
\text { Period }\end{array}$} & \multicolumn{4}{|c|}{$\begin{array}{c}\text { Doses de nitrogênio }(\mathrm{kg} / \mathrm{ha}) \\
\text { Doses of } N\end{array}$} & \multirow[t]{2}{*}{$\begin{array}{c}\text { Equação de regressão } \\
\text { Regression equation }\end{array}$} & \multirow[t]{2}{*}{$\mathrm{R}^{2}(\%)$} \\
\hline & 75 & 150 & 225 & 300 & & \\
\hline $\begin{array}{l}\text { Fev }-\mathrm{Abr} \\
F e b-A p r\end{array}$ & $41,55 \mathrm{a}$ & $37,10 \mathrm{a}$ & $44,46 a$ & $38,56 a$ & $\mathrm{Y}=40,42$ & \\
\hline $\begin{array}{l}\text { Mai - Ago } \\
\text { May - Aug }\end{array}$ & $11,38 b$ & $13,92 b$ & $14,30 \mathrm{~b}$ & $11,66 \mathrm{~b}$ & $\mathrm{Y}=12,81$ & \\
\hline $\begin{array}{l}\text { Set - Nov } \\
\text { Sep - Nov }\end{array}$ & $16,36 \mathrm{~b}$ & $17,71 \mathrm{~b}$ & $18,20 \mathrm{~b}$ & $19,14 b$ & $\bar{Y}=15,64+0,0117 * \mathrm{~N}$ & 96,75 \\
\hline
\end{tabular}

Médias seguidas pela mesma letra, na coluna, não diferem $(P>0,05)$ pelo teste Tukey.

Means followed by the same letter, in the column, do not differ $(P>0.05)$ by Tukey test.

* Significativo pelo teste $\mathrm{t}(\mathrm{P}<0,05)$

* Significant by t test $(P<0.05)$.

Tabela 4 - Estimativas dos coeficientes angulares (ß1) referentes às curvas de sobrevivência das gerações de perfilhos avaliadas nas quatro doses de $\mathrm{N}$

Table 4 - Estimates of the angular coefficients (B1) referring to the curves of survival of tillers generations under four doses of $N$

\begin{tabular}{|c|c|c|c|c|c|c|}
\hline \multirow[b]{2}{*}{$\begin{array}{l}\text { Geração de perfilhos } \\
\text { Generation of tillers }\end{array}$} & \multicolumn{4}{|c|}{$\begin{array}{c}\text { Doses de nitrogênio }(\mathrm{kg} / \mathrm{ha}) \\
\text { Doses of } N\end{array}$} & \multirow[t]{2}{*}{$\begin{array}{c}\text { Equação de regressão } \\
\text { Regression equation }\end{array}$} & \multirow[t]{2}{*}{$\mathrm{R}^{2}(\%)$} \\
\hline & 75 & 150 & 225 & 300 & & \\
\hline $\begin{array}{l}\text { Inicial } \\
\text { Beginning }\end{array}$ & $-0,0067$ & $-0,0094$ & $-0,0085$ & $-0,0081$ & $Y=-0,0082$ & - \\
\hline 1 & $-0,0026$ & $-0,0036$ & $-0,0047$ & $-0,0050$ & $Y=-0,0019-0,000011067 * \mathrm{~N}$ & 95,48 \\
\hline 2 & $-0,0019$ & $-0,0024$ & $-0,0035$ & $-0,0034$ & $Y=-0,0014-0,000007467 * N$ & 86,15 \\
\hline 3 & $-0,0014$ & $-0,0020$ & $-0,0018$ & $-0,0024$ & $Y=-0,0019$ & - \\
\hline 4 & $-0,0013$ & $-0,0010$ & $-0,0014$ & $-0,0017$ & $Y=-0,0014$ & - \\
\hline 5 & $-0,0022$ & $-0,0010$ & $-0,0031$ & $-0,0017$ & $Y=-0,0020$ & - \\
\hline 6 & $-0,0024$ & $-0,0034$ & $-0,0022$ & $-0,0020$ & $Y=-0,0025$ & - \\
\hline 7 & $-0,0020$ & $-0,0014$ & $-0,0013$ & $-0,0016$ & $Y=-0,0016$ & - \\
\hline 8 & $-0,0021$ & $-0,0040$ & $-0,0045$ & $-0,0021$ & $Y=-0,0032$ & - \\
\hline
\end{tabular}

Significativo pelo teste $t(P<0,05)$

* Significant byt test $(P<0.05)$. 
Tabela 5 - Taxas de sobrevivência de perfilhos basilares (perfilhos/100 perfilhos) em pastagem de Brachiaria decumbens adubadas com quatro doses de $\mathrm{N}$

Table 5 - $\quad$ Rates of survival of basal tillers (tillers/100 tillers) in a pasture of Brachiaria decumbens fertilized with four doses of $N$

\begin{tabular}{|c|c|c|c|c|c|c|}
\hline \multirow[b]{2}{*}{$\begin{array}{l}\text { Período } \\
\text { Period }\end{array}$} & \multicolumn{4}{|c|}{$\begin{array}{l}\text { Doses de nitrogênio (kg/ha) } \\
\text { Doses of } N\end{array}$} & \multirow[t]{2}{*}{$\begin{array}{c}\text { Equação de regressão } \\
\text { Regression equation }\end{array}$} & \multirow[t]{2}{*}{$\mathrm{R}^{2}(\%)$} \\
\hline & 75 & 150 & 225 & 300 & & \\
\hline $\begin{array}{l}\text { Fev - Abr } \\
\text { Feb-Apr }\end{array}$ & $75,41 \mathrm{a}$ & $79,86 \mathrm{a}$ & $72,50 \mathrm{a}$ & $78,40 \mathrm{a}$ & $\hat{Y}=76,54$ & \\
\hline $\begin{array}{l}\text { Mai - Ago } \\
\text { May - Aug }\end{array}$ & $69,27 \mathrm{a}$ & $66,73 b$ & $66,34 \mathrm{a}$ & $69,00 \mathrm{a}$ & $Y=67,83$ & \\
\hline $\begin{array}{l}\text { Set - Nov } \\
\text { Sep - Nov }\end{array}$ & $80,68 \mathrm{a}$ & $79,33 \mathrm{ab}$ & $78,84 \mathrm{a}$ & $77,90 \mathrm{a}$ & $Y=81,4-0,0118 * N$ & 96,75 \\
\hline
\end{tabular}

Médias seguidas pela mesma letra, na coluna, não diferem $(P>0,05)$ pelo teste Tukey.

Means followed by the same letter, in the column, do not differ $(P>0.05)$ by Tukey test.

* Significativo pelo teste $\mathrm{t}(\mathrm{P}<0,05)$

* Significant by $t$ test $(P<0.05)$

setembro/novembro (Tabela 5). Essa resposta, associada ao efeito linear positivo nas taxas de aparecimento e mortalidade neste mesmo período, reforça a hipótese de que o $\mathrm{N}$ acelerou a renovação dos perfilhos neste período do ano. Na pastagem, este efeito foi positivo, pois melhorou a estrutura do dossel, com porcentagem de folha superior à de colmo.

No mês de fevereiro, ocorreu maior passagem de perfilhos vegetativos para reprodutivos. A partir deste mês, houve decréscimo na porcentagem de perfilhos reprodutivos até os meses de agosto a novembro, quando praticamente não ocorreu florescimento (Tabela 6).

Esse padrão de florescimento da Brachiaria decumbens pode ter sido provocado pelo veranico em fevereiro (Tabela 1). Outro fator que pode ter contribuído para o amadurecimento dos perfilhos nesta época foi a renovação por perfilhos jovens, quando as condições ambientais foram favoráveis (Tabela 1).

Os baixos percentuais de perfilhos reprodutivos são decorrentes também da altura de manejo fixada $(20 \mathrm{~cm}), \mathrm{o}$ que limitou o florescimento da Brachiaria decumbens.

No período de fevereiro a abril, o número de perfilhos $/ \mathrm{m}^{2}$ foi superior $(\mathrm{P}<0,05)$ aos de maio a agosto e de setembro a novembro com as doses de 150,225 e $300 \mathrm{~kg} / \mathrm{ha}$ de $\mathrm{N}$, enquanto, com a dose de $75 \mathrm{~kg} /$ ha de $\mathrm{N}$, não houve diferença $(\mathrm{P}>0,05)$ (Tabela 7). Esta constatação é reflexo das condições de ambiente favoráveis ao perfilhamento, mesmo com as maiores taxas de mortalidade (Tabela 3), compensadas pela maior taxa de aparecimento de perfilhos (Tabela 2).

$\mathrm{O}$ número de perfilhos em função das doses de $\mathrm{N}$ se ajustou ao modelo linear somente no período de fevereiro a abril (Tabela 7), o que reflete a associação entre o nutriente e as condições climáticas favoráveis, como observado por outros autores em gramíneas de clima temperado (Langer, 1963; Nelson \& Zarrough, 1981; McKenzie, 1998; Bahmani et al., 2002) e em gramíneas de clima tropical (Alexandrino
Tabela 6 - Porcentagens de perfilhos reprodutivos em pastagem de Brachiaria decumbens adubadas com quatro doses de $\mathrm{N}$

Table 6 - $\quad$ Percentages of reproductive tillers in a pasture of Brachiaria decumbens fertilized with four doses of $N$

\begin{tabular}{|c|c|c|c|c|c|}
\hline \multirow[t]{2}{*}{$\begin{array}{l}\text { Mês } \\
\text { Month }\end{array}$} & \multicolumn{4}{|c|}{$\begin{array}{c}\text { Doses de nitrogênio }(\mathrm{kg} / \mathrm{ha}) \\
\text { Doses of } N\end{array}$} & \multirow[b]{2}{*}{$\begin{array}{l}\text { Média } \\
\text { Average }\end{array}$} \\
\hline & 75 & 150 & 225 & 300 & \\
\hline $\begin{array}{l}\text { Fevereiro } \\
\text { February }\end{array}$ & 7,4 & 11,2 & 5,0 & 11,1 & 8,7 \\
\hline $\begin{array}{l}\text { Março } \\
\text { March }\end{array}$ & 1,6 & 2,0 & 3,5 & 2,2 & 2,3 \\
\hline $\begin{array}{l}\text { Abril } \\
\text { April }\end{array}$ & 2,0 & 2,4 & 2,6 & 1,5 & 2,1 \\
\hline $\begin{array}{l}\text { Maio } \\
\text { May }\end{array}$ & 1,2 & 3,5 & 4,1 & 4,0 & 3,2 \\
\hline $\begin{array}{l}\text { Junho } \\
\text { June }\end{array}$ & 1,1 & 1,4 & 2,4 & 2,3 & 1,8 \\
\hline $\begin{array}{l}\text { Julho } \\
\text { July }\end{array}$ & 0 & 1,1 & 1,1 & 1,3 & 0,9 \\
\hline $\begin{array}{l}\text { Agosto } \\
\text { August }\end{array}$ & 0 & 0,3 & 0,2 & 0,9 & 0,3 \\
\hline $\begin{array}{l}\text { Setembro } \\
\text { September }\end{array}$ & 0 & 0,2 & 0,6 & 0,1 & 0,2 \\
\hline $\begin{array}{l}\text { Outubro } \\
\text { October }\end{array}$ & 0 & 0 & 0 & 0,6 & 0,1 \\
\hline $\begin{array}{l}\text { Novembro } \\
\text { November }\end{array}$ & 0 & 0 & 0,2 & 0,1 & 0,1 \\
\hline $\begin{array}{l}\text { Média } \\
\text { Average }\end{array}$ & 1,3 & 2,2 & 2,0 & 2,4 & 2,0 \\
\hline
\end{tabular}

et al., 1999; Garcez Neto et al., 2002; Oliveira et al., 2000; Martuscello et al., 2005).

A adubação nitrogenada influenciou somente o número de perfilhos vegetativos, possivelmente em razão do efeito do N no aumento da "ocupação de sítios" (Lemaire, 1985, citado por Nabinger \& Pontes, 2001), pois o número de perfilhos mortos manteve-se constante e independente das doses de $\mathrm{N}$ e dos períodos de avaliação (Tabela 8), apesar do efeito na taxa de mortalidade (Tabela 3 ).

A variação estacional da densidade populacional de perfilhos em cada dose de $\mathrm{N}$, de acordo com as datas de 
Tabela 7 - Densidade populacional de perfilhos vegetativos (perfilhos $/ \mathrm{m}^{2}$ ) em pastagem de Brachiaria decumbens adubadas com quatro doses de $\mathrm{N}$

Table 7 - Population densities of vegetative tillers (tillers $/ \mathrm{m}^{2}$ ) in pasture of Brachiaria decumbens in the four doses of $N$

\begin{tabular}{|c|c|c|c|c|c|c|}
\hline \multirow[b]{2}{*}{$\begin{array}{l}\text { Período } \\
\text { Period } \\
\end{array}$} & \multicolumn{4}{|c|}{$\begin{array}{l}\text { Doses de nitrogênio (kg/ha) } \\
\text { Doses of } N\end{array}$} & \multirow[t]{2}{*}{$\begin{array}{l}\text { Equação de regressão } \\
\text { Regression equation }\end{array}$} & \multirow[t]{2}{*}{$\mathrm{R}^{2}(\%)$} \\
\hline & 75 & 150 & 225 & 300 & & \\
\hline $\begin{array}{l}\text { Fev - Abr } \\
\text { Feb-Apr }\end{array}$ & $1618 \mathrm{a}$ & $2240 \mathrm{a}$ & 3202 a & 3525 a & $\bar{Y}=976+8,91 * * N$ & 96,94 \\
\hline $\begin{array}{l}\text { Mai - Ago } \\
\text { May - Aug }\end{array}$ & 1376 a & $1224 \mathrm{~b}$ & $1490 \mathrm{~b}$ & $1924 \mathrm{c}$ & $Y=1458$ & - \\
\hline $\begin{array}{l}\text { Set - Nov } \\
\text { Sep - Nov }\end{array}$ & $1196 \mathrm{a}$ & $1346 \mathrm{~b}$ & $1712 b$ & $2586 \mathrm{~b}$ & $\hat{Y}=1755$ & - \\
\hline
\end{tabular}

Médias seguidas pela mesma letra, na coluna, não diferem $(P>0,05)$ pelo teste Tukey.

Means followed by the same letter, in the column, do not differ $(P>0.05)$ by Tukey test.

* Significativo pelo teste $t(P<0,05)$

* Significant by $t$ test $(P<0.05)$.

Tabela 8 - Densidade populacional de perfilhos mortos (perfilhos $/ \mathrm{m}^{2}$ ) em pastagem de Brachiaria decumbens adubadas com quatro doses de $\mathrm{N}$

Table 8 - Population densities of dead tillers (tillers $/ \mathrm{m}^{2}$ ) in pasture of Brachiaria decumbens fertilized with four doses of $N$

\begin{tabular}{|c|c|c|c|c|c|}
\hline \multirow[b]{2}{*}{$\begin{array}{l}\text { Período } \\
\text { Period }\end{array}$} & \multicolumn{4}{|c|}{$\begin{array}{c}\text { Doses de nitrogênio }(\mathrm{kg} / \mathrm{ha}) \\
\text { Doses of } N\end{array}$} & \multirow[t]{2}{*}{$\begin{array}{l}\text { Média } \\
\text { Average }\end{array}$} \\
\hline & 75 & 150 & 225 & 300 & \\
\hline $\begin{array}{l}\text { Fev - Abr } \\
F e b-A p r\end{array}$ & 1144 a & 1093 a & 1093 a & $1034 \mathrm{a}$ & $Y=1050$ \\
\hline $\begin{array}{l}\text { Mai - Ago } \\
\text { May - Aug }\end{array}$ & $1120 \mathrm{a}$ & $1226 \mathrm{a}$ & 1376 a & $1010 \mathrm{a}$ & $\hat{Y}=1183$ \\
\hline $\begin{array}{l}\text { Set - Nov } \\
\text { Sep - Nov }\end{array}$ & 941 a & 834 a & $991 \mathrm{a}$ & $928 \mathrm{a}$ & $\bar{Y}=923$ \\
\hline
\end{tabular}

Médias seguidas pela mesma letra, na coluna, não diferem $(P>0,05)$ pelo teste Tukey.

Means followed by the same letter, in the column, do not differ $(P>0.05)$ by Tukey test.

avaliação, está apresentada na Figura 1. As linhas indicam a sobrevivência de perfilhos com o passar das avaliações e o espaço preenchido entre as linhas representa a contribuição de cada geração na população total de perfilhos marcados.

A dinâmica das gerações de perfilhos comprovou que a retirada dos animais logo após a data D3 (27/04/03), quando as condições de ambiente tornaram-se desfavoráveis ao crescimento da gramínea, manteve uma média de $55 \%$ do número de perfilhos no inverno e no início da primavera, independentemente da dose de N. A manutenção dessa porcentagem foi importante para garantir a rápida renovação dos perfilhos basilares no final do mês de setembro, o que possibilitou o retorno dos animais aos piquetes nos meses de outubro e novembro.

No início das avaliações, em fevereiro de 2003, a densidade de perfilhos apresentou valores elevados, em decorrência das condições ambientais favoráveis do período e do efeito imediato da segunda fração da dose de N. Neste período as maiores densidades populacionais de perfilhos basilares ocorreram nos tratamentos com maiores doses de N (Figura 1). A partir da data D1 (24/02/03) as densidades de perfilhos basilares diminuíram, em razão do florescimento ocorrido no mês de fevereiro.
Na data D3 (27/04/03), ocorreu decréscimo acentuado na densidade de perfilhos nas doses de 225 e $300 \mathrm{~kg} / \mathrm{ha} \mathrm{de}$ $\mathrm{N}$, ocasionado pela morte de perfilhos jovens que apareceram em D1 (24/02/03) e D2 (24/03/03), como conseqüência da grande população de perfilhos maiores por unidade de área, que causou sombreamento aos perfilhos mais jovens, provocando sua senescência.

Para as doses de 75 e $150 \mathrm{~kg} / \mathrm{ha}$ de N, esta diminuição não foi tão acentuada, em razão do menor número de perfilhos por área, permitindo boa luminosidade nas camadas mais baixas do dossel e desenvolvimento de perfilhos jovens.

Em D4 (29/05/03), houve pequeno aumento no número de perfilhos com a dose $225 \mathrm{~kg} / \mathrm{ha}$ de $\mathrm{N}$ e manutenção do número de perfilhos na dose de $300 \mathrm{~kg} /$ ha de $\mathrm{N}$, que pode também ser resultado da mais drástica diminuição do número de perfilhos na data anterior. Conseqüentemente, ocorreu aumento da luminosidade nas camadas inferiores do dossel.

É importante ainda destacar que as gerações de perfilhos surgidas nas datas D3 e D4 (Figura 1) foram bastante expressivas e grande parte destes perfilhos permaneceu viva durante 

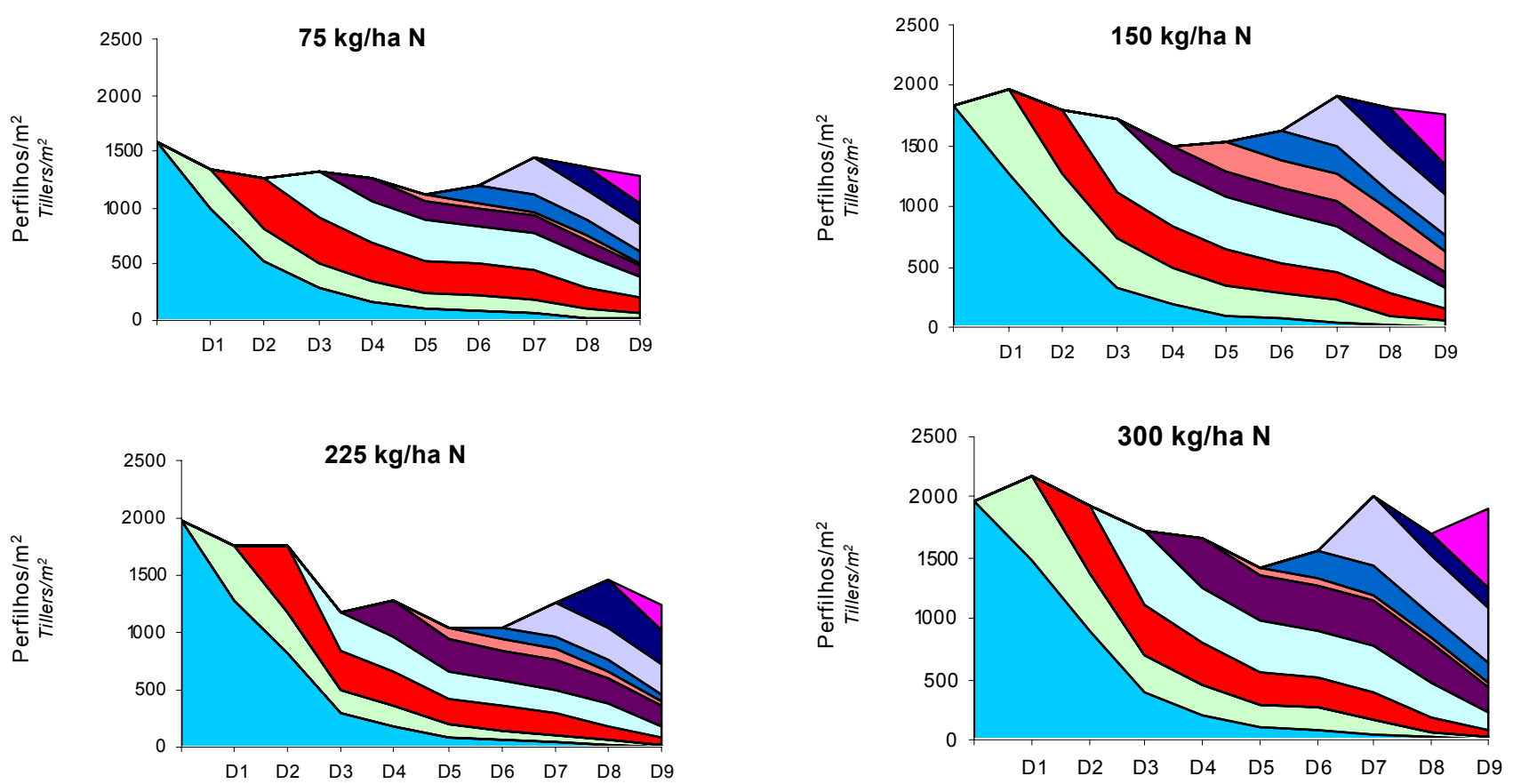

Figura 1 - Padrão estacional da densidade populacional de perfilhos basilares em pastagem de Brachiaria decumbens sob quatro doses de $\mathrm{N}$ e em diferentes datas de avaliação: $\mathrm{D} 1=24 / 02 / 03 ; \mathrm{D} 2=24 / 03 / 03 ; \mathrm{D} 3=27 / 04 / 03 ; \mathrm{D} 4=29 / 05 / 03 ;$ D5 = 16/07/03; D6 = 20/08/03; D7 = 20/09/03; D8 = 23/10/03; D9 = 21/11/03.

Figure 1 - Pattern season of the population density of basal tillers in a pasture of Brachiaria decumbens fertilized with four doses of nitrogen, at different evaluation dates: $D 1=24 / 02 / 03 ; D 2=24 / 03 / 03 ; D 3=27 / 04 / 03 ; D 4=29 / 05 / 03 ; D 5=16 / 07 / 03 ; D 6=20 / 08 / 03 ; D 7=20 / 09 / 03 ; D 8=23 / 10 / 03$; $D 9=21 / 11 / 03$.

Tabela 9 - Porcentagem de sobrevivência de cada geração de perfilhos (identificada pelo mês em que os perfilhos foram marcados) ao final do período experimental (novembro de 2003), em pastagem de Brachiaria decumbens sob quatro doses de $\mathrm{N}$

Table 9 - Survival percentage of each tiller generation (evaluation by monthly identification of new tillers) at the end of the experimental period (November of 2003) in pasture of Brachiaria decumbens under four doses of $N$

\begin{tabular}{|c|c|c|c|c|c|}
\hline \multirow[t]{2}{*}{$\begin{array}{l}\text { Geração } \\
\text { Generation }\end{array}$} & \multicolumn{4}{|c|}{$\begin{array}{l}\text { Dose de nitrogênio }(\mathrm{kg} / \mathrm{ha}) \\
\text { Dose of } N\end{array}$} & \multirow[b]{2}{*}{$\begin{array}{l}\text { Média } \\
\text { Average }\end{array}$} \\
\hline & 75 & 150 & 225 & 300 & \\
\hline $\begin{array}{l}\text { Inicial } \\
\text { Initial }\end{array}$ & 1,1 & 0,0 & 0,3 & 0,4 & 0,4 \\
\hline $\begin{array}{l}\text { Fevereiro } \\
\text { February }\end{array}$ & 4,3 & 2,9 & 1,6 & 0,9 & 2,4 \\
\hline $\begin{array}{l}\text { Março } \\
\text { March }\end{array}$ & 10,4 & 5,8 & 3,8 & 3,0 & 5,8 \\
\hline $\begin{array}{l}\text { Abril } \\
\text { April }\end{array}$ & 14,1 & 9,8 & 9,0 & 7,1 & 10,0 \\
\hline $\begin{array}{l}\text { Maio } \\
\text { May }\end{array}$ & 8,2 & 7,5 & 13,7 & 11,6 & 10,3 \\
\hline $\begin{array}{l}\text { Junho } \\
\text { June }\end{array}$ & 2,4 & 9,8 & 3,0 & 2,0 & 4,3 \\
\hline $\begin{array}{l}\text { Julho } \\
\text { July }\end{array}$ & 7,7 & 7,1 & 5,8 & 8,2 & 7,2 \\
\hline $\begin{array}{l}\text { Agosto } \\
\text { August }\end{array}$ & 18,9 & 19,5 & 20,0 & 24,0 & 20,6 \\
\hline $\begin{array}{l}\text { Setembro } \\
\text { September }\end{array}$ & 13,8 & 13,7 & 25,2 & 8,2 & 15,2 \\
\hline $\begin{array}{l}\text { Outubro } \\
\text { October }\end{array}$ & 19,1 & 23,7 & 17,5 & 34,7 & 23,8 \\
\hline
\end{tabular}

todo o período de outono e inverno. Estas duas gerações de perfilhos foram importantes para manutenção da perenidade da pastagem de Brachiaria decumbens, pois, além de apresentar elevado número de perfilhos, tiveram também alta taxa de sobrevivência. Ao final das avaliações (novembro 2003), as gerações de perfilhos das datas D3 e D4 participaram com $10 \%$ da população total de perfilhos (Tabela 9) e podem ter sido as mais importantes para a renovação dos perfilhos na pastagem, pois garantiram uma população adequada à produção de forragem no início da primavera seguinte e, conseqüentemente, reduziram o risco de degradação.

\section{Conclusões}

Maiores taxas de aparecimento e de mortalidade e mais alta densidade populacional de perfilhos basilares em Brachiaria decumbens sob lotação contínua ocorrem no período de fevereiro a abril.

As taxas de aparecimento de perfilhos de Brachiaria decumbens nos períodos de maio a agosto e setembro a novembro são proporcionais às doses de nitrogênio, como as taxas de mortalidade e sobrevivência são eqüivalentes no período de setembro a novembro. 
A densidade populacional de perfilhos é positivamente influenciada pela adubação nitrogenada no período de fevereiro a abril.

A manutenção da pastagem de Brachiaria decumbens a $20 \mathrm{~cm}$ sob lotação contínua favorece a renovação da densidade populacional de perfilhos no mês de setembro.

\section{Literatura Citada}

ALEXANDRINO, E.; NASCIMENTO JR., D.; MOSQUIM, P.R. et al. Efeito da adubação nitrogenada e da freqüência de corte na rebrotação da Brachiaria brizantha cv. Marandu. IICaracterísticas morfogênicas e estruturais. In: SIMPÓSIO INTERNACIONAL GRASSLAND ECOPHYSIOLOGY AND GRAZIVG ECOIOGY, 1999, Cunitlca.Anais... Curitiba, 1999. p. 287-290.

BAHMANI, I.; THOM, E.R.; MATTHEW, C. et al. Flowering propensity of two New Zealand perennial ryegrass cultivars originating from different ecotypes. New Zealand Journal of Agricultural Research, v.45, p.129-137, 2002.

CARVALHO, C.A.B.; DA SILVA, S.C.; SBRISSIA, A.F. et al. Demografia do perfilhamento e taxas de acúmulo de matéria seca em capim 'Tifton 85' sob pastejo. Scientia Agrícola, v.57, n.4, p.591-600, 2000.

CAVALCANTE, M.A.B. Características morfogênicas, estruturais e acúmulo de forragem em relvado de Brachiaria decumbens cv. Basilisk sob pastejo, em diferentes alturas. Viçosa, MG: Universidade Federal de Viçosa 2001. 64p. Dissertação (Mestrado em Zootecnia), Universidade Federal de Viçosa, 2001

DAVIES, A.; EVANS, M.E.; EXLEY, J.K. Regrowth of perennial ryegrass as affected by simulated leaf sheaths. Journal of Agricultural Science, v.101, p.131-137, 1983.

DEREGIBUS, V.A.; SANCHEZ, R.A.; CASAL, J.J. Effects of light quality on tiller production in Lolium $s p$. Plant Physiology, v.72, p.900-902, 1983

DEREGIBUS, V.A.; SANCHEZ, R.A.; CASAL, J.J. et al. Tillering responses to enrichment of red light beneath the canopy in humid natural grassland. Journal of Applied Ecology, v.22, p.199-206, 1985.

FAGUNDES, J.L.; FONSECA, D.M.; MOREIRA, L.M. et al. Acúmulo de forragem em pastos de Brachiaria decumbens Stapf. adubados com nitrogênio. Pesquisa Agropecuaria Brasileira, v.40, n. $4,2005$.

GARCEZ NETO, A.F.; NASCIMENTO JR., D.; REGAZZI, A.J. et al. Respostas morfogênicas e estruturais de Panicum Maximum cv. Mombaça sob diferentes níveis de adubação nitrogenada e alturas de corte. Revista Brasileira de Zootecnia, v.31, n.5, p.1890-1900, 2002.

HERNANDEZ GARAY, A.; MATTHEW, C.; HODGSON, J. Effect of spring management on perennial ryegrass and ryegrass-white clover pastures. 2. Tiller and growing point densities and population dynamics. New Zealand Journal of Agricultural Research, v.40, p.37-50, 1997.

HODGSON, J. Grazing management: science into practice. New Zealand: Longman Scientific and Technical, Longman Group, 1990. 203p.
KORTE, C.J. Tillering in 'Grasslands Nui' perennial ryegrass swards. 2. Seasonal pattern of tillering and age of flowering tillers with two mowing frequencies. New Zealand Journal of Agricultural Research, v.29, p.629-638. 1986.

LANGER, R.H.M. Tillering in herbage grass. A review. Herbage Abstracts, v.33, p.141-148, 1963.

MATTHEW, C.; ASSUERO S.G.; BLACK C.K. et al. Tiller dynamics in grazed swards. In: LEMAIRE, G.; HODGSON, J.; MORAES, H. et al. (Eds.) Grassland ecophysiology and grazing ecology of natural grasslands. Wallingford: CAB International, 2000. p.109-133.

McKENZIE, F.R. The influence of applied nitrogen on the vigour of Lolium perenne during the establishment year under subtropical conditions. Tropical Grasslands, v.30, 345-349. 1996.

McKENZIE, F.R. Influence of applied nitrogen on vegetative, reproductive, and aerial tiller densities in Lolium perenne L. during the establishment year. Australian Journal of Agricultural Research, v.49, p.707-711, 1998.

MARTUSCELLO, J.A.; FONSECA, D.F.; NASCIMENTO JR., D. et al. Características morfogênicas e estruturais do capim-xaraés submetido à adubação nitrogenada e desfolhação. Revista Brasileira de Zootecnia, v.34, n.5, p.1475-1482, 2005.

MOZZER, O.L. Capim-elefante - curso de pecuária leiteira. Coronel Pacheco: EMBRAPA/CNPGL. 2.ed. 1993. (Documento, 43).

NABINGER, C.; PONTES, L.S. Morfogênese de plantas forrageiras e estrutura do pasto. In: SIMPÓSIO SOBRE MANEJO DA PASTAGEM, 18., 2001, Piracicaba. Anais... Piracicaba: Fundação de Estudos Agrários Luiz de Queiroz, 2001. p.755-771.

NABINGER, C. Princípios da exploração intensiva de pastagem. In: SIMPÓSIO SOBRE MANEJO DA PASTAGEM, 13. Piracicaba. Anais... Piracicaba: Fundação de Estudos Agrários Luiz de Queiroz, 1996. p.59-121.

NELSON, C.J.; ZARROUGH, K.M. Tiller density and tiller weight as yield determinants of vegetative swards. In: WRIGHT, C.E. (Eds.) Plant physiology and herbage production. London: British Grassland Society, 1981, p.25-29 (Occasional Symposium, 13)

OLIVEIRA, M.A.; PEREIRA, O.G.; HUAMAN, C.A.M. et al. Características morfogênicas e estruturais do capim-bermuda tifton 85 (Cynodon spp.) em diferentes idades de rebrota. Revista Brasileira de Zootecnia, v.29, n.6, p.1339-1948, 2000 .

SANTOS, P.M.; CORSI, M.; BALSALOBRE, M.A.A. Efeito da freqüência de pastejo e da época do ano sobre a produção e a qualidade em Panicum maximum (Jacq.) cvs. Tanzânia e Mombaça. Revista Brasileira de Zootecnia, v.28, n.2, p.244$249,1999$.

UEBELE, M.C. Padrões demográficos de perfilhamento e produção de forragem em pastos de capim-Mombaça submetidos a regimes de lotação intermitente. Piracicaba: Escola Superior de Agricultura Luiz de Queiroz, 2002. 76p. Dissertação (Mestrado em Ciência Animal e Pastagem) - Escola Superior de Agricultura Luiz de Queiroz, 2002.

Recebido: 09/12/04 Aprovado:02/09/05 